\title{
PERSPECTIVE
}

\section{Macular oedema: the role of soluble mediators}

\author{
David Kent, Stanley A Vinores, Peter A Campochiaro
}

Extracellular accumulation of fluid resulting in oedema is well tolerated in most tissues of the body, but in the retina, it results in dysfunction of retinal neurons. Collection of fluid in the macula is called macular oedema and when the fovea is involved, it results in decreased visual acuity. Macular oedema occurs in a wide variety of ocular diseases and is one of the most prevalent causes of vision loss in developed countries. It is the most common cause of vision loss in patients with diabetic retinopathy ${ }^{1}$ and in other ischaemic retinopathies such as branch and central retinal vein occlusion. ${ }^{23}$ Macular oedema is also a major cause of decreased vision following intraocular surgery. In the literature, the term cystoid macular oedema (CMO) is often used to describe oedema occurring after surgery, ${ }^{4}$ because collection of fluid in the macula often results in cystic changes that are visible by ophthalmoscopy. However, cystic changes can occur with any type of macular oedema, and therefore the term post-surgical macular oedema is preferred when referring to oedema occurring after any type of intraocular procedure. Macular oedema is also a frequent complication of uveitis regardless of aetiology ${ }^{5}$ and is commonly seen in patients with retinitis pigmentosa. ${ }^{6}$ Thus, macular oedema is a component of many different types of pathological conditions and is an enormous clinical problem.

\section{Macular oedema results from breakdown of the blood-retinal barrier}

Extravascular accumulation of fluid in the retina is normally prevented by the blood-retinal barrier (BRB). The BRB consists of adaptations of retinal blood vessels (inner $\mathrm{BRB}$ ) and the retinal pigmented epithelium (RPE; outer BRB) that control access of fluid and solutes to the retina. One adaptation is the presence of tight junctions between adjacent retinal vascular endothelial (RVE) cells and between adjacent RPE cells. Other adaptations include an abatement in vesicular transport in RVE cells compared with vascular endothelial cells in $\operatorname{skin}^{78}$ and asymmetrical distribution of proteins that regulate vectorial transport across RPE cells. ${ }^{9}$

Breakdown of the BRB can occur in a variety of ways. Any insult involving RVE or RPE cells results in BRB breakdown that is usually repaired rapidly unless the source of damage is persistent. For example, laser photocoagulation results in death of RPE cells with accompanying BRB breakdown, but the barrier is rapidly re-established by repopulation of the involved area with $\mathrm{RPE}$ cells that form tight junctions. ${ }^{10}$ In patients with diabetic retinopathy, death of pericytes results in microaneurysm formation and focal vascular leakage. ${ }^{112}$ Focal leakage may be due to loss of pericyte and/or glial derived signals or structural changes in endothelial cells caused by microaneurysm formation. ${ }^{13}$ In addition, there is often diffuse breakdown of the BRB in these patients and in patients with other ischaemic retinopathies, which is not associated with identifiable structural changes. ${ }^{14}$ Fluores- cein angiography demonstrates staining of vessel walls and leakage from retinal vessels adjacent to areas of ischaemic retina, ${ }^{15}$ suggesting that a diffusible agent released by ischaemic retina may be involved. In patients with macular oedema occurring after cataract surgery, the surgical wound is remote from RVE and RPE cells, while in patients with macular oedema due to uveitis, inflammatory cells are often limited to the anterior chamber and/or anterior vitreous, again suggesting that diffusible factors are involved.

\section{Current treatments for macular oedema are empirical and often ineffective}

Since the molecular mechanisms of various types of macular oedema are unknown there are no specific treatments. Instead, non-specific anti-inflammatory treatment is used for all types of macular oedema except that associated with ischaemic retinopathies for which laser treatment is used. After cataract surgery, topical non-steroidal antiinflammatory drugs (NSAIDs) help to prevent angiographic macular oedema and result in some improvement in vision in some patients who have had macular oedema for more than 6 months. ${ }^{16}{ }^{17}$ However, some NSAIDs have been implicated in corneal melts occurring after cataract or refractive surgery. Corticosteroids have not been proved to be effective in a randomised, placebo controlled study, but are frequently used for the treatment of macular oedema. Acetozolamide provides some small benefit for certain types of macular oedema. ${ }^{18}$ Many patients with macular oedema do not benefit from current treatments, and therefore new, specific treatments are needed.

\section{Soluble factors implicated in BRB breakdown}

In ischaemic retinopathies, vascular endothelial growth factor (VEGF) and adenosine, released from the ischaemic tissue, are capable of causing BRB breakdown and contributing to macular oedema. ${ }^{19-21}$ Histamine has also been implicated as a possible mediator of BRB dysfunction in patients with diabetes. ${ }^{22} 23$ Systemic administration ${ }^{24}$ or sustained intravitreous releas $\mathrm{e}^{25}$ of insulin-like growth factor 1 (IGF-1) causes breakdown of the BRB. Recently a somatostatin analogue that antagonises IGF-1 has been demonstrated to decrease idiopathic macular oedema ${ }^{26}$ and macular oedema associated with ocular inflammatory disease (PM van Hagen, personal communication, March 1999), suggesting that IGF-1 may play a part in several types of macular oedema.

Ocular tissues respond to injury, including surgical trauma, by the activation of phospholipases which in turn cause release of membrane phospholipids. Activation of phospholipase A2 is the first step in the synthesis of lipid second messengers, including prostaglandins (PGs), leukotrienes, and platelet activating factor (PAF). PAF, the most active inflammatory mediator known, ${ }^{27}$ has been shown to promote vascular permeability in a number of different vascular beds ${ }^{27-30}$ including the retinal 
vasculature. ${ }^{31}$ PGs are thought to contribute to the pathogenesis of post-surgical and inflammatory macular oedema for several reasons. Firstly, PGE1, PGE2, and PGF2 $\alpha$ are produced in the iris as a result of surgical trauma and increased levels may persist for weeks after surgery. ${ }^{4}{ }^{32} 33$ Secondly, PGs can cause disruption of the blood-retinal and the blood-aqueous barriers. ${ }^{19}{ }^{34}{ }^{35}$ Finally, indomethacin, an inhibitor of PG synthesis, reduces both the incidence and severity of macular oedema after lens extraction ${ }^{46}$ and the PGE activity in the aqueous humour of postoperative eyes. ${ }^{43}$

Tumour necrosis factor $\alpha(\mathrm{TNF} \alpha)$ and interleukin 1 (IL-1) $\alpha$ and $\beta$ are proinflammatory cytokines that have been implicated in ocular inflammatory diseases. ${ }^{37}$ Intravitreous injection of $\mathrm{TNF} \alpha$ or IL- $1 \beta$ causes BRB breakdown and infiltration with inflammatory cells similar to that seen in experimental autoimmune uveoretinitis (EAU) and other models of inflammatory eye diseases. ${ }^{38-42}$ In addition, rats with EAU show dramatic upregulation of VEGF that is temporally and spatially correlated with BRB breakdown. ${ }^{43}{ }^{44}$ Therefore, VEGF, which is known to be associated with macular oedema in ischaemic retinopathies, may also contribute to macular oedema in ocular inflammatory disorders. The finding that octreotide, a somatostatin analogue, shows some benefit for macular oedema in ocular inflammatory diseases would also tend to support a role for IGF-1.

\section{Animal models for macular oedema}

It is difficult to model macular oedema, because only higher animals have a macula and because it is a chronic disease process. In addition, the pathophysiology may be very different in different disease settings and our understanding of its pathophysiology in any setting is incomplete. For these reasons, much of our efforts have focused on pathological specimens from patients with macular oedema. ${ }^{13} 45-49$ These studies have provided important insights. For instance, the correlation of VEGF expression with sites of BRB breakdown in eyes of patients with choroidal melanomas ${ }^{49}$ was the first suggestion that VEGF may contribute to BRB breakdown, both in ischaemic retinopathies and other disease processes. However, testing mechanistic hypotheses requires animal models.

Models of post-surgical macular oedema in monkeys mimic important features of the disease in humans, ${ }^{50}{ }^{51}$ but are extremely expensive and are not feasible for biochemical or molecular investigations. Diabetic animals, including humans, develop mild breakdown of the BRB soon after the onset of hyperglycaemia, ${ }^{52}$ but it is not clear if this has any relevance to macular oedema, which does not develop until years later.

There are models of ocular inflammatory disease, the best characterised of which is EAU which has been established in both rats ${ }^{5354}$ and mice. ${ }^{55}{ }^{56}$ EAU is a very severe form of uveitis, which provides a brief period in its early stages when it can be used to study the effects of ocular inflammation on the BRB, after which there is destruction of the retina. IL- $1 \beta$ and $\mathrm{TNF} \alpha^{57}$ have been implicated as mediators of inflammatory cell recruitment and, although it has not been directly demonstrated, it is thought that these mediators may also contribute to BRB breakdown.

An alternative approach to the modelling of disease processes associated with macular oedema is to perform intravitreous injections of mediators suspected to play a part in these disorders to study their effects on the BRB. Studies of this type in rabbits have provided insights regarding potential mediators and the mechanisms by which they compromise the BRB, ${ }^{19} 313758-60$ but although rabbit retinal vessels have tight junctions and form a BRB, their limited distribution to the central retina and the rela- tive lability of the $\mathrm{BRB}$ in rabbits, raise questions regarding the relevance of findings in rabbits to human disease processes. Rats and mice have holangiotic retinas that are similar to humans in most respects, except for the absence of a macula. This is probably not of major consequence because while macular oedema derives its name from the part of the retina where oedema has visual significance, leakage and oedema are not limited to the macula; there is diffuse leakage from retinal vessels, and to a lesser extent through the RPE. ${ }^{13} 48$

Investigations aimed at understanding the causes of BRB breakdown and how it can be treated or prevented can therefore be done in rodents. Intravitreal injection of TNF $\alpha$, IL-1 $\beta$, or IL-8, but not IL-6, causes BRB breakdown in Lewis rats. ${ }^{38-41}$ Comparison of the effects on the $\mathrm{BRB}$ of injection of $\mathrm{TNF} \alpha$, IL- $1 \beta$, or VEGF to ultrastructural changes seen in the BRB in rats with EAU showed many similarities supporting the validity of this approach and suggesting that these particular mediators may be involved. ${ }^{42}$ A histamine $\mathrm{H}_{2}$ receptor antagonist significantly inhibited the IL- $1 \beta$ induced breakdown of the $\mathrm{BRB}$ in rats, suggesting that the IL-1 $\beta$ effect on the BRB is mediated, at least in part, through histamine. ${ }^{40}$ Additional studies such as these are needed to compare and contrast the acute effects on the BRB of potential mediators of macular oedema, but it is also important to investigate long term effects.

One way to investigate long term effects is to utilise sustained release of agents from implants in the vitreous cavity. To investigate this issue, we incorporated VEGF into sustained release polymers and implanted them into the vitreous cavity of rabbits or primates. ${ }^{20}$ There were some differences in the effect of VEGF on the retinal vasculature between primates and rabbits, adding to our reservations regarding the use of rabbits for these types of studies, but in both rabbits and primates, there was severe BRB breakdown. In primates, there was retinal oedema, including macular oedema, confirming that sustained exposure of VEGF to the retina results in macular oedema.

A more practical approach to investigate the long term effects of VEGF on the retina is to generate transgenic mice with sustained increased expression of potential mediators in the eye. We are currently utilising Rhodopsin promoter/VEGF transgenic mice with photoreceptor specific expression of $\mathrm{VEGF}^{61}$ to determine the effect of sustained increased expression of VEGF on the BRB.

\section{Direct and indirect actions of potential mediators of} macular oedema

Based upon vascular leakage studies in rabbit skin, VEGF, histamine, and bradykinin have been classified as direct action mediators because the onset of leakage is rapid and peaks within 30 minutes, no neutrophils are required, and antagonists to PAF have no effect. ${ }^{62}$ The same conclusion regarding VEGF being a direct acting agent was reached based upon studies in rat brain, ${ }^{63}$ but a study using the Miles assay in guinea pigs ${ }^{64}$ has suggested that VEGF increases permeability indirectly through nitric oxide and PGs. Measuring vascular permeability in several tissues after intradermal injections of VEGF in rats, Sirois and Edelman $^{65}$ found that in some tissues, but not others, VEGF appears to act through PAF. Conversely, in other studies, PAF has been suggested to increase permeability through VEGF, ${ }^{66}$ nitric oxide, ${ }^{6667}$ or PGs. ${ }^{28}{ }^{30}$ Therefore, the situation is complex and it is difficult to predict what interactions exist in the retina based upon studies in other vascular beds.

With regard to the retinal vasculature, there is a paucity of information, mostly derived from studies in rabbit eyes. It has been suggested that $\mathrm{TNF} \alpha$ and IL- $1 \beta$ act synergisti- 
cally in rabbit eyes to increase permeability of retinal vessels, partially mediated through PGs, but independent of PAF, ${ }^{59}{ }^{60}$ while, in another study, IL- $1 \alpha$ was found to act indirectly through both $\mathrm{PGs}$ and $\mathrm{PAF}^{58}$ In Lewis rats, IL-1 $\beta$ appears to act indirectly through histamine. ${ }^{41}$ Additional studies are needed to clarify the interactions, because there are important therapeutic implications.

In summary, macular oedema is a major cause of visual loss in a large number of ocular conditions. Treatments are empirical and often ineffective. There is evidence suggesting that soluble mediators play a part, but the specific agents involved in each disease process and the manner in which they interact is unknown. Defining the details of the molecular mechanisms in various disease processes is critical for the development of specific therapies.

Supported by PHS grant EY10017, EY05951, EY12609, and core grant P30EY1765 from the National Eye Institute, Lew R Wasserman Merit Awards (PAC and SAV) and an unrestricted grant from Research to Prevent Blindness, Inc, the Rebecca P Moon, Charles M Moon, Jr, and Dr P Thomas Manchester Research Fund, a grant from Mrs Harry J Duffey, a grant from Dr and Mrs William Lake, a grant from Project Insight, and a grant from the Association for Retinopathy of Prematurity and Related Diseases. PAC is the George S and Retinopathy of Prematurity and Related Diseases. PAC is the Geo
Dolores Dore Eccles Professor of Ophthalmology and Neuroscience.

DAVID KENT

STANLEY A VINORES PETER A CAMPOCHIARO

Departments of Ophthalmology and Neuroscience, The Johns Hopkins University School of Medicine, Maumenee 719, $600 \mathrm{~N}$ Wolfe Street, Baltimore, MD 21287-9277, USA

Correspondence to: Peter A Campochiaro

pcampo@jhmi.edu

1 Patz A, Schatz H, Berkow JW, et al. Macular edema: an overlooked complication of diabetic retinopathy. Trans Am Acad Ophthalmol Otolaryngol 1973;77:34-42.

2 The Branch Vein Occlusion Study Group. Argon laser photocaogulation for macular edema in branch vein occlusion. Am f Ophthalmol 1984;98:27182

3 The Central Vein Occlusion Study Group. Evaluation of grid pattern photocoagulation for macular edema in central vein occlusion. Ophthalmology 1995;102:1425-33.

4 Miyake K. Indomethacin in the treatment of postoperative cystoid macular edema. Surv Ophthalmol 1984;28:554-68.

5 Rothova A, Suttorp-vanSchulten MSA, Treffers WF, et al. Causes and frequency of blindness in patients with intraocular inflammatory disease. Brf Ophthalmol 1996;80:332-6.

6 Fetkenhour CL, Choromokos E, Weinstein J, et al. Cystoid macular edema in retinitis pigmentosa. Trans Am Acad Ophthalmol Otolaryngol 1977;83: 515-21.

7 Sagaties MJ, Raviola G, Schaeffer S, et al. The structural basis of the inner blood-retinal barrier in the eye of Macaca mulatta. Invest Ophthalmol Vis Sci 1997;28:2000-14

8 Stewart PA, Tuor UI. Blood-eye barriers in the rat: correlation of ultrastructure with function. $\mathcal{f}$ Comp Neurol 1994;340:566-76.

9 Rizzolo LJ. Polarity and the development of the outer blood-retinal barrier. Histol Histopathol 1997;12:1057-67.

10 Richardson PR, Boulton ME, Duvall-Young J, et al. Immunocytochemical study of retinal diode laser photocoagulation in the rat. Br $\mathrm{f}$ Ophthalmol 1996;80:1092-8.

11 Cogan DG, Kuwabara T. The mural cell in perspective. Arch Ophthalmol 1967;78:133-9.

12 Engerman R, Bloodworth JMB, Nelson S. Relationship of microvascular disease in diabetes to metabolic control. Diabetes 1977;26:760-9.

13 Vinores SA, Campochiaro PA, Lee A, et al. Localization of blood-retinal barrier breakdown in human pathologic specimens by immunohistochemical staining for albumin. Lab Invest 1990;62:742-50.

14 Bresnick GH. Diabetic maculopathy: a critical review highlighting diffuse macular edema. Ophthalmology 1983;90:1301-7.

15 Yanoff M, Fine BS, Brucker AJ, et al. Pathology of human cystoid macular edema. Surv Ophthalmol 1984;28(Suppl):505-11.

16 Flach AJ, Stegman RC, Graham J, et al. Prophylaxis of aphakic cystoid macular edema without corticosteroids. A paired-comparison, placebomacular edema without corticosteroids. A paired-comparison, pla
controlled double-masked study. Ophthalmology 1990;97:1253-8.

17 Flach AJ, Dolan BJ, Irvine AR. Effectiveness of ketorolac tromethamine $0.5 \%$ ophthalmic solution for chronic aphakic and pseudophakic cystoid macular edema. Am f Ophthalmol 1987;103:479-86.

18 Cox SN, Hay E, Bird AC. Treatment of chronic macular edema with acetazolamide. Arch Ophthalmol 1988;106:1190-5.

19 Vinores SA, Sen H, Campochiaro PA. An adenosine agonist and prostaglandin E1 cause breakdown of blood-retinal barrier by opening tight junctions between vascular endothelial cells. Invest Ophthalmol Vis Sci 1992;33:1870-8

20 Ozaki H, Hayashi H, Vinores SA, et al. Intravitreal sustained release of VEGF causes retinal neovascularization in rabbits and breakdown of the blood-retinal barrier in rabbits and primates. Exp Eye Res 1997;64:505-17.

21 Murata T, Nakagawa K, Khalil A, et al. The relation between expression of vascular endothelial growth factor and breakdown of the blood-retinal barvier in diabetic rat retinas. Lab Invest 1996;74:819-25.

22 Enea NA, Hollis TM, Kern JA, et al. Histamine H1 receptors mediate increased blood-retinal barrier permeability in experimental diabetes. Arch Ophthalmol 1989;107:270-4
23 Gardner TW, Eller AW, Friberg TR, et al. Antihistamines reduce blood-retinal barrier permeability in type I (insulin-dependent) diabetic patients with nonproliferative retinopathy. A pilot study. Retina 1995;15: $134-40$

24 Hussain MA, Studer K, Messer EP, et al. Treatment with insulin-like growth factor I alters capillary permeability in skin and retina. Diabetes 1995;44:1209-12.

25 Grant MB, Mames RN, Fitzgerald C, et al. Insulin-like growth factor I acts as an angiogenic agent in rabbit cornea and retina: comparative studies with basic fibroblast growth factor. Diabetologia 1993;36:282-91.

26 Kuijpers RW, Baarsma S, van Hagen PM. Treatment of cystoid macular edema with octreotide. N Engl f Med 1998;338:624-6.

27 Predescu D, Ihida K, Predescu S, et al. The vascular distribution of the platelet-activating factor receptor. Eur f Cell Biol 1996;69:86-98.

28 De Lima WT, Kwasniewski FH, Sirois P, et al. Studies on the mechanism of PAF-induced vasopermeability in rat lungs. Prostaglandins Leukot Essen Fatty Acids 1995;52:245-9.

29 Rhee CK, Park YS, Long SA, et al. Effects of platelet activating factor on vascular permeability of the middle ear mucosa. Ann Otol Rhinol Laryngol 1997;106:604-7.

30 Fujii E, Irie K, Uchida Y, et al. Role of eicosanoids but not nitric oxide in the platelet activating factor-induced increase in vascular permeability in mouse skin. Eur f Pharmacol 1995;273:267-72.

31 Smith D, Lee EK, Saloupis P, et al. Role of neutrophils in breakdown of the blood-retinal barrier following intravitreal injection of platelet-activating factor. Exp Eye Res 1994;59:425-32.

32 Bazan NG. Metabolism of arachidonic acid in the retina and retinal pigment epithelium: biological effects of oxygenated metabolites of arachidonic acid. Prog Clin Biol Res 1989;312:15-37.

33 Mishima H, Masuda K. Clinical implications of prostaglandins and synthesis inhibitors. In: Leopold IH, Burns RP, eds. Symposium on ocular therapy. New York: John Wiley, 1977;10:1-19.

34 Neufeld AH, Sears ML. The site of action of prostaglandin E2 on the disruption of the blood-aqueous barrier in the rabbit eye. Exp Eye Res 1973; 17:445-8

35 Vegge T, Neufeld AH, Sears ML. Morphology of the breakdown of the blood-aqueous barrier in the ciliary processes of the rabbit eye after prostaglandin E2. Invest Ophthalmol Vis Sci 1975;14:33-6.

36 Miyake K. Prophylaxis of aphakic cystoid macular edema using topical indomethacin. $\mathcal{F}$ Am Intraocul Implant Soc 1978;4:174-9.

37 Claudio L, Martiney JA, Brosnan CF. Ultrastructural studies of the bloodretinal barrier after exposure to interleukin-1 beta or tumor necrosis factoralpha. Lab Invest 1994;70:850-61.

38 Ferrick MR, Thurau SR, Opppenheim MH, et al. Ocular inflammation stimulated by intravitreal interleukin-8 and interleukin-1. Invest Ophthalmol Vis Sci 1991;32:1534-9.

39 Bamforth SD, Lightman S, Greenwood J. The effect of TNF-alpha and IL-6 on the permeability of the rat blood-retinal barrier in vivo. Acta Neuropath 1996;91:624-32.

40 Bamforth SD, Lightman SL, Greenwood J. Interleukin-1 $\beta$-induced disruption of the retinal vascular barrier of the central nervous system is mediated through leukocyte recruitment and histamine. Am F Pathol 1997;150:32940

41 Bamforth SD, Lightman SL, Greenwood J. Ultrastructural analysis of interleukin-1 beta-induced leukocyte recruitment to the rat retina. Invest Ophthalmol Vis Sci 1997;38:25-35.

42 Luna JD, Chan CC, Derevjanik NL, et al. Blood-retinal barrier (BRB) breakdown in experimental autoimmune uveoretinitis: comparison with vascular endothelial growth factor, tumor necrosis factor alpha, and interleukin-1 beta-mediated breakdown. 7 Neurosci Res 1997;49:268-80.

43 Vinores SA, Youssri AI, Luna JD, et al. Upregulation of vascular endothelial growth factor in ischemic and non-ischemic human and experimental retinal disease. Histol Histopathol 1997;12:99-109.

44 Vinores SA, Chan C-C, Vinores MA, et al. Increased vascular endothelial growth factor (VEGF) and transforming growth factor-beta (TGF-beta) in experimental autoimmune uveoretinitis: upregulation of VEGF without neovascularization. F Neuroimmunol 1998;89:43-50.

45 Vinores SA, Gadegbeku C, Campochiaro PA, et al. Immunohistochemical localization of blood-retinal barrier breakdown in human diabetics. $A m \mathcal{F}$ Pathol 1989; 134:231-5.

46 Vinores SA, Van Niel E, Swerdloff JL, et al. Electron microscopic immunocytochemical demonstration of blood-retinal barrier breakdown in human diabetics and its association with aldose reductase in retinal vascular endothelium and retinal pigment epithelium. Histochem f 1993;25:648-63.

47 Vinores SA, Küchle M, Derevjanik NL, et al. Blood-retinal barrier breakdown in retinitis pigmentosa: light and electron microscopic breakdown in retinitis pigmentosa: light and electro

48 Vinores SA, Amin A, Derevjanik NL, et al. Immunohistochemical localization of blood-retinal barrier breakdown sites associated with post-surgical macular edema. Histochem f 1994;26:655-65

49 Vinores SA, Küchle M, Mahlow J, et al. Blood-ocular barrier breakdown in eyes with ocular melanoma. A potential role for vascular endothelial growth factor/vascular permeability factor. Am f Pathol 1995;147:1289-97.

50 Tso MOM, Shih CY. Disruption of blood-retinal barrier in ocular hypotony: preliminary report. Exp Eye Res 1976;23:209-16.

51 Tso MOM, Shih CY. Experimental macular edema after lens extraction. Invest Ophthalmol Vis Sci 1977;16:381-92.

52 Cunha-Vaz JG, De Abreu JRF, Campos AJ, et al. Early breakdown of the blood-retinal barrier in diabetes. Brf Ophthalmol 1975;59:649-56.

53 DeKozak Y, Sakai J, Thillaye B, et al. S antigen-induced experimental autoimmune uveoretinitis in rats. Curr Eye Res 1981;1:327-37.

54 Forrester JV, Liversidge J, Dua HS, et al. Experimental autoimmune uveoretinitis: a model system for immunomodulation. Curr Eye Res 1992;11(suppl):33-40.

55 Caspi RR, Roberge FG, Chan C-C, et al. A new model of autoimmune disease: experimental autoimmune uveoretinitis induced in mice with two different retinal antigens. F Immunol 1988;140:1490-5.

56 Chan C-C, Caspi RR, Ni M, et al. Pathology of experimental autoimmune uveoretinitis in mice. F Autoimmun 1990;3:247-55.

57 Yoshida $M$, Yoshimura N, Hangai $M$, et al. Interleukin-1a, interleukin-1b, and tumor necrosis factor gene expression in endotoxin-induced uveitis. Invest Ophthalmol Vis Sci 1994;35:1107-13. 
58 Rubin RM, Rosenbaum JT. A platelet-activating factor antagonist inhibits interleukin 1-induced inflammation. Biochem Biophys Res Comm 1988;154: interleuk.

59 Fleisher L, Ferrell J, McGahan C. Mediators of the ocular inflammatory response to interleukin-1 beta plus tumor necrosis factor-alpha.Graefes Arch Clin Exp Ophthalmol. 1995;233:94-100.

60 Fleisher LN, Ferrell JB, McGahan MC. Synergistic uveitic effects of tumor necrosis factor-alpha and interleukin-1 beta. Invest Ophthalmol Vis Sci 1992;33:2120-7.

61 Okamoto N, Tobe T, Hackett SF, et al. Transgenic mice with increased expression of vascular endothelial growth factor in the retina: a new model of intraretinal and subretinal neovascularization. Am $\mathcal{F}$ Pathol 1997;151: 281-91.

62 Collins PD, Connolly DT, Williams TJ. Characterization of the increase in vascular permeability induced by vascular permeability factor in vivo. $\mathrm{Br} \mathcal{F}$ Pharmacol 1993;1993:195-9.
63 Dobrogowska DH, Lossinsky AS, Tarnawski M, et al. Increased blood-brain barrier permeability and endothelial abnormalities induced by vascular endothelial growth factor. $\mathcal{F}$ Neurocytol 1998;27:163-73.

64 Murohara T, Horowitz JR, Silver M, et al. Vascular endothelial growth factor/vascular permeability factor enhances vascular permeability via nitric oxide and prostacyclin. Circulation 1998;97:99-107.

65 Sirois MG, Edelman ER. VEGF effect on vascular permeability is mediated by synthesis of platelet-activating factor. Am $\mathcal{7}$ Physiol 1997;272:H2746-56.

66 Ahmed A, Dearn S, Shams M, et al. Localization, quantification, and activation of platelet-activating factor receptor in human endometrium during the menstrual cycle: PAF stimulates NO, VEGF, and FAKpp125. FASEB f 1998;12:831-43.

67 Ramirez MM, Quardt SM, Kim D, et al. Platelet activating factor modulates microvascular permeability through nitric oxide synthesis. Microvasc Res 1995;50:223-34. 